\title{
APLICAÇÃO DO REGULAMENTO TÉCNICO DE QUALIDADE NA EFICIÊNCIA ENERGÉTICA DA CONSTRUÇÃO DE UM PRÉDIO PÚBLICO
}

\author{
Raísa Brandão Gaspar \\ Mestranda em Sistemas de Gestão (UFF), Rio de Janeiro, RJ, Brasil \\ ra.brandao.gaspar@gmail.com
}

José Luiz Fernandes

Pós-Doutor em Engenharia, Dept. de Engenharia de Produção - CEFET/RJ, Rio de Janeiro, RJ, Brasil jluizfernandes@gmail.com

\section{RESUMO}

O presente artigo trata da aplicação de diretrizes de eficiência energética nos projetos na construção de edificações no setor público. O tema será desenvolvido através da aplicação do Manual RTQ-C (2014) para prédios públicos utilizando como estudo de caso o projeto de um prédio a ser construído numa Instituição Federal de Ensino no Rio de Janeiro. A busca por um melhor desempenho energético surge no cenário atual como um dos principais elementos de suporte para a racionalização de recursos de energia. A questão da obrigatoriedade legal para o cumprimento em novas edificações do setor público, tornou-se ponto fundamental para justificar a otimização do processo de sua aplicação.

Palavras-chave: Sustentabilidade. Eficiência Energética. Edifícios Públicos.

\section{APPLICATION OF THE TECHNIQUES REGULATION OF QUALITY IN THE ENERGY EFFICIENCY OF THE GOVERNMENT CONSTRUCTION BUILDING}

\begin{abstract}
This article deals with the application of energy efficiency guidelines in design of buildings's construction in the public sector. The theme was developed through the application of the RTQ-C Manual with version 2014, for public buildings using as a case study the design of a building to be built in a Federal Educational Institution in Rio de Janeiro. The search for better energy performance appears in the current scenario as one of the main support elements for the rationalization of energy resources. The issue of legal obligation to comply with new buildings in the public sector has become a fundamental point to justify the optimization of the process of its application.
\end{abstract}

Key Words: Sustentability. Energy resources. Government sector buildings.

\section{INTRODUÇÃO}

De acordo com Romero (2012) constantes crises energéticas mundiais foram propulsoras para a busca por métodos e pesquisas mais sustentáveis na transmissão e consumo final de 
energia. Segundo Picchi e Agopyan (1993), a questão da eficiência energética se apresenta como uma diretriz para a elaboração de projetos e análise dos ambientes construídos.

As edificações são responsáveis do consumo excessivo de energia, de acordo com a Associação Brasileira das Empresas de Serviços de Conservação de Energia, o índice de desperdício em alguns anos, equivale a metade da produção da Usina de Itaipu. Desta forma, a atuação do projetista se torna fundamental, tendo em vista que o conhecimento de critérios de eficiência energética em edificações e suas aplicações ainda ao nível do projeto, podem reduzir significativamente o consumo final de energia. (ROMERO, 2012).

O uso de técnicas gerenciais juntamente com sistemas de gestão da qualidade são ferramentas aplicadas na busca da melhoria nas obras de construção civil e no ambiente construído. E com a evolução da gestão da qualidade, o enfoque passou a ser mais sistêmico, culminando na criação de parâmetros e orientações através das séries de normas ISO 9000. (PICCHI e AGOPYAN, 1993).

No âmbito governamental, a administração pública tem o poder de gerar grandes mudanças na obtenção de resultados através de modelos de qualidade, tendo em vista que o mesmo tem a prerrogativa de exigir qualidade, prazo e custo dos serviços prestados. Além disso, o princípio norteador da eficiência visa sempre o melhor resultado com menor uso de recursos possíveis. (PEREZ, 2011)

A metodologia empregada neste artigo será a avaliação de projeto de prédio de sala de aulas do CEFET-RJ, segundo o Manual do Regulamento Técnico da Qualidade (RTQ-C, 2014) para prédios públicos, comerciais e de serviços, visando delimitar os requisitos para atendimento dos parâmetros da eficiência energética e os principais desafios a sua implantação. As principais etapas desenvolvidas neste artigo consistem em:

1) Aquisição de dados do projeto em relação a envoltória, iluminação e sistema de ar condicionado;

2) Aplicação das diretrizes do Regulamento Técnico da Qualidade para edifícios públicos, comerciais e de serviços (RTQ-C, 2014) através do Método Descritivo;

3) Análise da aplicabilidade de pontos extras gerados pelas bonificações do bom uso da energia e redução do desperdício.

4) Análise dos resultados do nível de eficiência para a envoltória, iluminação e sistema de ar condicionado.

5) Inserção de medidas corretivas na construção do projeto buscando a otimização da eficiência energética na construção. 
O estudo de caso foi realizado em um projeto arquitetônico de um prédio de 7 andares com salas de aula a ser construído em uma Instituição de Ensino Federal no Rio de Janeiro, onde foram aplicadas as diretrizes no Regulamento Técnico da Qualidade do Nível de Eficiência Energética de Edifícios Comerciais, de Serviços e Públicos (RTQ-C, 2014).

\section{REVISÃO BIBLIOGRÁFICA}

\subsection{Introdução Histórica}

Desde o início do uso da eletricidade na segunda década do século XIX até o final dos anos de 1960, a questão da eficiência energética não foi considerada. A preocupação com o tema se iniciou a partir da crise do petróleo em 1973 e com o aumento da população nos centros urbanos na década de 80, pois nessa época sistemas de iluminação e climatização artificial eram utilizados em grande escala, ocasionando assim uma grande crise na oferta de energia e iniciando os primeiros estudos visando o aumento da eficiência energética e redução de consumo. (ROMERO, 2012)

A formalização de uma regulamentação sobre o tema ocorreu durante a década de 70 , de maneira pioneira na Europa. Entretanto, o conceito de certificação das edificações usando como diretriz as características energéticas só surgiu em 1993, com a promulgação da Diretiva Europeia 93/76/CEE. Porém, essa diretiva não tinha caráter obrigatório e devido a isso houve uma baixa adesão gerando baixo impacto na economia de energia.

No Brasil, a noção de eficiência energética nas edificações surge com o Decreto № 34.979, de 23 de Novembro de 1993 (BRASIL, 1993) com o Programa Estadual de Conservação de Energia nas Edificações do Rio Grande do Sul. A medida visava à promoção do uso de fontes energéticas alternativas nas edificações e a proposição de normas, padrões e outros instrumentos técnicos e legais a serem adotados para incentivar a melhoria e a conservação da eficiência energética nas edificações e desta forma reduzir o seu consumo. (CARLO e LAMBERTS, 2010)

Em 2001, após a crise energética local, intensificou-se uma preocupação com as questões ambientais, relacionadas principalmente com o consumo excessivo de energia elétrica, o que levou à criação da Lei $n^{\circ} 10.295$ (BRASIL, 2001), que dispõe sobre a Política de Conservação de Energia.

Porém, somente em 2010 (Portaria Inmetro № 372, de 17 de Setembro de 2010) (BRASIL, 2010) com revisão em 2012 (Portaria Inmetro no 17, de 16 de Janeiro de 2012) (BRASIL, 2012), os esforços do governo foram efetivamente concretizados em um processo de etiquetagem de 
edificações para o Brasil (inicialmente para edifícios comerciais, de serviços e públicos), obtida através de avaliação dos requisitos contidos no Regulamento Técnico da Qualidade do Nível de Eficiência Energética de Edifícios Comerciais, de Serviços e Públicos, o RTQ-C (2014).

Este Regulamento passou por mais uma atualização em 2014, com a Portaria n¹26 do Inmetro (BRASIL, 2014), em que foi considerado a inserção de parâmetros de eficiência visando os ambientes que foram utilizados durante os Jogos Olímpicos de 2016, no Rio de Janeiro e os que foram construídos para utilização durante a Copa do Mundo de 2014, sediada no Brasil.

Esse documento é complementado pelo Regulamento de Avaliação da Conformidade do Nível de Eficiência Energética de Edifícios Comerciais, de Serviços e Públicos (RAC-C), que apresenta o processo de avaliação das características do edifício para etiquetagem junto ao Laboratório de Inspeção acreditado pelo Inmetro.

Para o setor público, a instauração de legislação específica só ocorreu no ano de 2014, através da Instrução Normativa $n^{\circ} 2$, que se aplica às obras novas acima de $500 \mathrm{~m}^{2}$ e também a prédios que passarem por reformas significativas. Existem dois tipos de etiquetas: a do projeto e a da obra construída. Atualmente, apenas o Organismo de Inspeção em Eficiência Energética de Edificações (OI3E) da Fundação Certi é habilitado pelo Inmetro para atribuir a etiqueta de eficiência. (NAKAMURA, MACIEL e CARLO, 2013)

A aplicação da avaliação da eficiência energética nas edificações é um requisito que visa qualificar a edificação no âmbito da sustentabilidade. Esse tipo de análise do projeto e ambiente construído apresenta um grande potencial de aplicação graças ao desenvolvimento de novas tecnologias para o uso nos sistemas construtivos. A questão da qualidade visa criar projetos que visem a redução dos desperdícios de energia e o conforto e satisfação do usuário final. (NAKAMURA, MACIEL e CARLO, 2013)

\subsection{O manual RTQ-C}

O RTQ-C (2014) fornece uma classificação de edifícios através da determinação da eficiência de três sistemas: 1) Envoltória, 2) Iluminação, 3) Condicionamento de ar e 4) Bonificações.

A classificação em edifícios pode ser obtida em apenas um sistema, deixando os demais em aberto. Neste caso, no entanto, não é fornecida uma classificação geral da edificação, mas apenas do (s) sistema (s) analisado(s). 
A classificação da envoltória, faz-se através da determinação de um conjunto de índices referentes às características físicas da edificação. Componentes opacos e dispositivos de iluminação zenital são definidos nos pré-requisitos, enquanto as aberturas verticais são avaliadas através de equações específicas. Estes parâmetros compõem a "pele" da edificação (como cobertura, fachada e aberturas), e são complementados pelo volume, pela área de piso da edificação e pela orientação das fachadas.

A eficiência da iluminação é determinada calculando a densidade de potência instalada pela iluminação interna, de acordo com as diferentes atividades exercidas pelos usuários de cada ambiente. Quanto menor a potência utilizada, menor é a energia consumida e mais eficiente é o sistema, desde que garantidas as condições adequadas de iluminação.

A classificação da eficiência do sistema de condicionamento de ar pode ser dividida em duas classes diferentes. Uma classe está relacionada aos sistemas individuais e split, já classificados pelo INMETRO. Desta forma, deve-se apenas consultar os níveis de eficiência fornecidos nas etiquetas do INMETRO para cada um dos aparelhos instalados na edificação para posteriormente aplicar o resultado na equação geral da edificação.

A outra classe que trata a eficiência de sistemas de condicionamento de ar do tipo central, que não são classificados pelo INMETRO devem seguir prescrições definidas no texto do regulamento.

Desta forma, a classificação do nível de eficiência destes sistemas é mais complexa, pois sua definição depende da verificação de um número de requisitos e não pode ser simplesmente obtida pela consulta da etiqueta.

Após a finalização do cálculo da eficiência dos três sistemas: Envoltória, lluminação e Condicionamento de Ar, os resultados parciais são inseridos na equação geral para verificar o nível de eficiência global da edificação. Os formatos da Etiqueta Nacional de Conservação de Energia (ENCE), conforme está ilustrado na figura 1, contêm os níveis de classificação finais e parciais da edificação.

No entanto, o cálculo dos níveis de eficiência parciais e do nível geral de eficiência pode ser alterado tanto por bonificações, que podem elevar a eficiência, quanto por pré-requisitos que, se não cumpridos, podem reduzir esses níveis. As bonificações constituem-se de pontos extras que visam incentivar o uso de energia solar para aquecimento de agua, uso racional de agua, cogeração, entre outros. Já os pré-requisitos são de caráter obrigatório, referem-se a cada sistema em particular e também ao edifício por completo. 
Figura 1 - Etiqueta Nacional de Conservação de Energia Geral

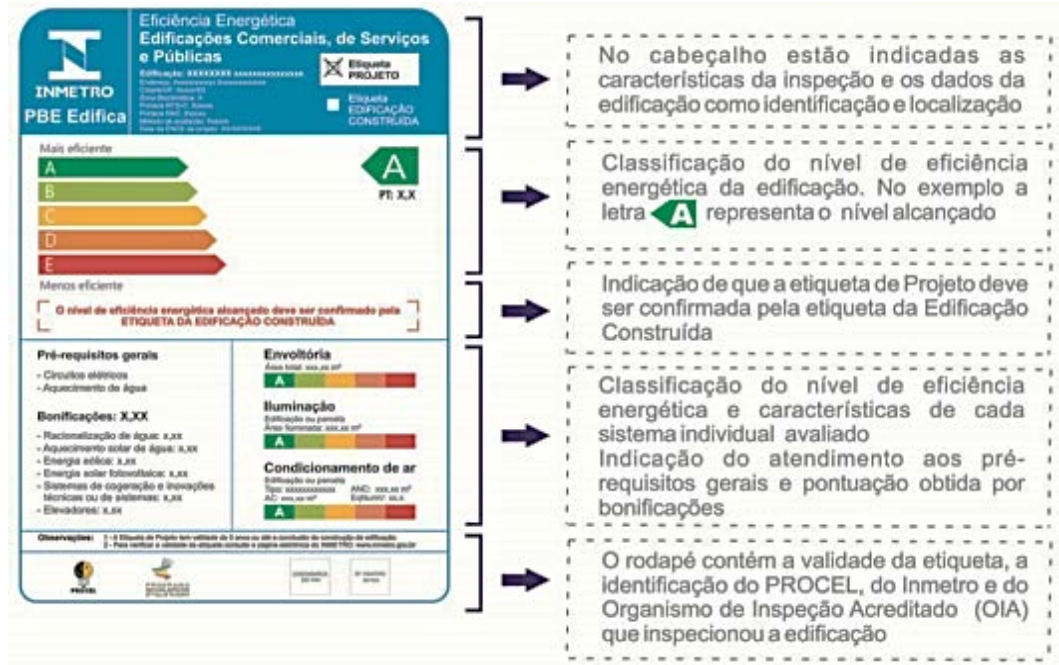

Fonte: (CB3e, 2014)

A classificação do projeto de construção de acordo com a eficiência energética, usando como base o manual RTQ-C (2014), é calculada através da equação (1), em que o resultado é um valor que classifica a edificação, como ilustrado na Tabela 1.

$$
\mathrm{PT}=0,30 \cdot\left\{\left(\text { EqNumEnv. } \frac{\mathrm{AC}}{\mathrm{AU}}\right)+\left(\frac{\mathrm{APT}}{\mathrm{AU}} \cdot 5+\frac{\mathrm{ANC}}{\mathrm{AU}} \text { EqNumV }\right)\right\}+0,30 \cdot(\text { EqNumDPI })+0,40 \cdot\left\{\left(\text { EqNumCA. } \frac{\mathrm{AC}}{\mathrm{AU}}\right)+\left(\frac{\mathrm{APT}}{\mathrm{AU}} \cdot 5+\frac{\mathrm{ANC}}{\mathrm{AU}} \cdot \text { EqNumV }\right)\right\}+\underbrace{(1)}_{0}
$$

Onde: EqNumEnv: equivalente numérico da envoltória; EqNumDPI: equivalente numérico da iluminação, identificado pela sigla DPI, de Densidade de Potência de Iluminação; EqNumCA: equivalente numérico do sistema de ar condicionado; EqNumV: equivalente numérico de ambiente não condicionados e/ou ventilados naturalmente; APT: área útil dos ambientes de permanência transitória, desde que não condicionados; $A N C$ : área útil dos ambientes não condicionados de permanência prolongada, com comprovação de percentual de horas ocupadas de conforto por ventilação natural (POC) através do método da simulação; $A C$ : área útil dos ambientes condicionados; $A U$ : área útil; $b$ : pontuação obtida pelas bonificações, que varia de zero a 1.

Com o resultado da equação, é possível chegar a classificação geral do edifício, como ilustrado na tabela 1.

Tabela1 - Classificação geral do edifício

\begin{tabular}{|c|c|c|c|c|}
\hline A & B & C & D & E \\
\hline$\geq 4,5$ a 5 & $\geq 3,5$ a $>4,5$ & $\geq 2,5$ a $>3,5$ & $\geq 1,5$ a $>2,5$ & $<1,5$ \\
\hline
\end{tabular}

Fonte: (Adaptado do RTQ-C, 2014) 


\section{ESTUDO DE CASO}

O estudo de caso visa analisar e classificar, o projeto de construção, de uma nova edificação para uso educacional, de acordo com a eficiência energética, usando como base o manual RTQ-C (2014). O edifício para ser elegível à etiquetagem deve cumprir os seguinte tópicos: a) Pré-requisitos gerais, b) Bonificações, c) Pré-requisitos específicos.

Os pré-requisitos gerais são necessários para a obtenção da classificação geral do nível de eficiência da edificação. No entanto, caso os mesmos não sejam atendidos não há o impedimento para as classificações parciais, mas ocorre o impedimento da obtenção de uma etiqueta completa de nível de eficiência A, B ou C. São considerados pré-requisitos: a.1) Envoltória: a envoltória é considerada a pele da edificação (cobertura, fachadas e aberturas), a avaliação desse item é feito através da análise das características físicas da construção e complementadas através do volume, orientação das fachadas e área de piso; a.2) Circuitos elétricos: a edificação deve possuir circuitos separados por uso final (iluminação, ar condicionado etc.). A exceção ocorre para hotéis que possuam desligamento automático nos quartos, edificações com múltiplas unidades autônomas de consumo e edificações que foram construídas antes de Junho de 2009; a.3) Aquecimento de água: se aplica a edificações que possuam elevada demanda de água quente como academias, hospitais, clubes, restaurantes. Em edifícios de uso misto, este pré-requisito é aplicável a parcelas de uso comercial, de serviços e público que possuam uma demanda de água quente igual ou maior a $10 \%$ da demanda total instalada de energia para essa parcela.

As bonificações (item b) são itens de utilização de sistemas ou equipamentos que racionalizem o uso da água, tais como, torneiras com arejadores e/ou temporizadores, sanitários com sensores, aproveitamento de água pluvial e de outras fontes alternativas de água, essas medidas devem garantir uma economia mínima de $40 \%$ no consumo anual de água do edifício, considerando práticas correntes de dimensionamento. Os pré-requisitos específicos são particulares a cada um dos itens de análise do projeto baseado nos parâmetros de eficiência energética.

\subsection{Análise da Envoltória}

O item da envoltória apresenta pré-requisitos específicos, mostrado no quadro 1, que devem ser considerados para atingir os níveis de classificação desejados. Os itens de transmitância 
térmica, cores e absortância são obtidos através da NBR 15220/2003 (ABNT, 2003). A iluminação zenital são todas as aberturas feitas na cobertura da edificação.

O edifício, inicialmente está apto a ter classificação B, C ou D, (Equação 1 e Tabela 1), pois o mesmo não possui nenhum tipo de iluminação zenital, que é uma das exigências para categoria $A$ do manual, prevista em projeto.

O edifício localiza-se no Rio de Janeiro, por isso faz parte da Zona Bioclimática 8, conforme ilustrado na figura 2, classifica as regiões do Brasil de acordo com as variações climáticas existentes no território. Essa delimitação pelo clima foi feita pela ABNT e toma por base 300 cidades que tiveram seus padrões mapeados e usados como parâmetros para o zoneamento.

Figura 2 - Zoneamento Bioclimático Brasileiro

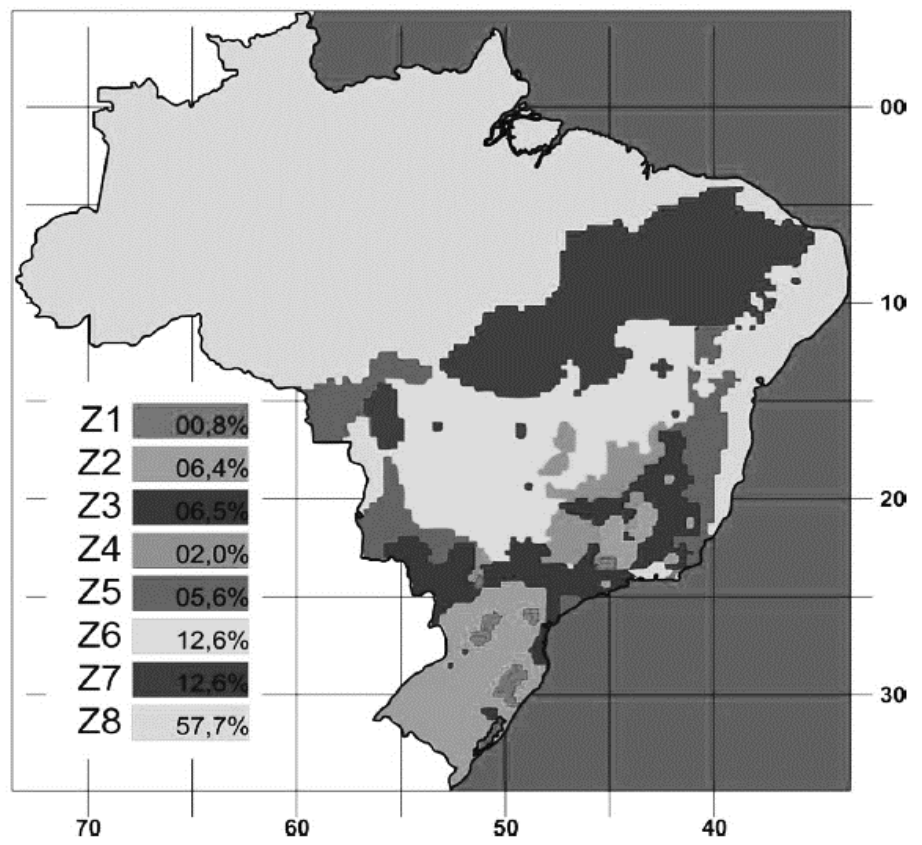

Fonte: (RTQ-C, 2014)

O item da envoltória apresenta pré-requisitos específicos, ilustrado no quadro 1, que devem ser considerados para atingir os níveis de classificação desejados. Os itens de transmitância térmica, cores e absortância são obtidos através da NBR 15.220/2003. A iluminação zenital são todas as aberturas feitas na cobertura da edificação.

\begin{tabular}{c|c|c|c}
\multicolumn{4}{c}{ Quadro 1 - Síntese dos pré-requisitos específicos da envoltória } \\
\hline $\begin{array}{c}\text { Nível de } \\
\text { eficiência }\end{array}$ & $\begin{array}{c}\text { Transmitância térmica da } \\
\text { cobertura e paredes } \\
\text { exteriores }\end{array}$ & $\begin{array}{c}\text { Cores e absortância } \\
\text { de superfícies }\end{array}$ & $\begin{array}{c}\text { Iluminação } \\
\text { zenital }\end{array}$ \\
\hline A & $\mathrm{X}$ & $\mathrm{X}$ & $\mathrm{X}$ \\
\hline $\mathrm{B}$ & $\mathrm{X}$ & $\mathrm{X}$ & $\mathrm{X}$ \\
\hline C e D & $\mathrm{X}$ & & \\
\hline
\end{tabular}

Fonte: (Adaptado do Manual RTQ-C, 2014) 
Conforme dito anteriormente, o edifício para ser elegível à etiquetagem deve cumprir inicialmente o tópico relativo ao Pré-requisitos gerais e consumo da envoltória. a) Pré-requisito: Transmitância térmica da parede e cobertura; b) Pré-requisito: Absortância solar e cores; c) Cálculo do Índice de Consumo da Envoltória (Ic env).

Para a análise da Transmitância térmica da parede e da cobertura, tem-se que a transmitância térmica da cobertura, de acordo com os dados do RTQ-C (2014), o índice encontrado não está dentro do aceitável tendo em vista que atingir o nível $\mathrm{A}$ deve-se ter 1,0 W $\left(\mathrm{m}^{2} . \mathrm{K}\right)$ para ambientes condicionados e no projeto em questão o valor foi $2,97 \mathrm{~W}\left(\mathrm{~m}^{2} . \mathrm{K}\right)$, que foi encontrado a partir da multiplicação entre a transmitância térmica e média das áreas dos dois tipos de lajes existentes: laje nervurada e maciça, ambas com forro de gesso como acabamento. Para este parâmetro a edificação ficou classificada como nível E pois não tinha os requisitos necessários.

$\mathrm{Na}$ transmitância térmica das paredes o valor do índice foi será $2,36 \mathrm{~W}\left(\mathrm{~m}^{2} \cdot \mathrm{K}\right)$, sendo considerado o fechamento com tijolos cerâmicos $(29 \times 19 \times 9 \mathrm{~cm})$ rebocado nas duas faces e com revestimento externo tipo porcelanato, dados esses colhidos no projeto e memorial descritivo do mesmo. Esse item obteve categoria $\mathrm{C}$.

Em relação ao pré-requisito da transmitância das paredes e coberturas, o edifício ficou com a classificação nível E. A cobertura foi o item, que levou a classificação mais baixa, pois a cobertura atual se apresenta como laje impermeabilizada, sem nenhum tipo de cobertura com telha ou qualquer outro elemento que diminuísse a incidência direta dos raios solares.

Para análise do Pré-requisito da absortância solar e cores, tem-que as cores usadas na envoltória da edificação, os pré-requisitos correspondentes são os de absortância solar menor ou igual a 0,50 para paredes e coberturas. E após a análise dos materiais da fachada no projeto, observa-se que na fachada será colocado revestimento tipo porcelanato na cor cinza claro, como não há esse tipo de especificação na NBR 15220/2003, utilizou-se o parâmetro para o reboco na cor clara entre 0,30 e 0,50 desta forma, o requisito foi atendido, tendo em vista que a absortância prevista é menor ou igual a 0,50.

Para o índice da absortância da cobertura, considerou-se o valor de 0,65 a 0,80 que é o equivalente ao concreto aparente, que no caso é o tipo de acabamento mais próximo ao usado no projeto. O requisito não foi atendido, tendo em vista que de acordo NBR 15220/2003 o valor encontrado é maior que 0,50. Conclui-se então que o pré-requisito de absortância não foi atendido totalmente pelo projeto, sendo considerado por isso reprovado neste item. (GASPAR, 2015) 
Para o Cálculo do Índice de Consumo da Envoltória (Ic env), utilizou-se os dados ilustrados na tabela 2. (GASPAR, 2015)

Tabela 2 - Dados do projeto

\begin{tabular}{l|l}
\hline \multicolumn{2}{c}{ Dados do projeto } \\
\hline Zona bioclimática & ZB 8 \\
\hline Área de projeção do edifício & Ape $=394,17 \mathrm{~m}^{2}$ \\
\hline Área total construída & Atot $=2080,19 \mathrm{~m}^{2}$ \\
\hline Área da envoltória & Aenv $=1956,15 \mathrm{~m}^{2}$ \\
\hline Área de projeção da cobertura & Apcob $=297,17 \mathrm{~m}^{2}$ \\
\hline Ângulo Vertical de Sombreamento & AVS $=45^{\circ}$ \\
\hline Ângulo Horizontal de Sombreamento & AHS $=0$ \\
\hline Fator de Forma (Aenv/ Vtot) & FF $($ Aenv $/$ Vtot $)=0,27$ \\
\hline Fator Altura, (Apcob/ Atot) & FA (Apcob/ Atot $)=0,14$ \\
\hline Fator solar & FS $=0,80$ \\
\hline Percentual de Abertura na Fachada total & PAFT $=0,21$ \\
\hline Volume total da edificação & Vtot: $7072,57 \mathrm{~m}^{3}$ \\
\hline
\end{tabular}

Fonte: (Adaptado de GASPAR, 2015)

Com os dados obtidos e após aplicar a equação 1, tem-se que os resultados ilustrados na tabela 3.

Tabela 3 - Dados dos intervalos dos níveis de eficiência para o edifício analisado

\begin{tabular}{cccccc}
\hline EFICIÊNNCIA & A & B & C & D & E \\
\hline Lim mín & & 214,31 & 222,26 & 230,20 & 238,14 \\
\hline Lim Máx & 214,30 & 222,25 & 230,19 & 238,13 & \\
\hline
\end{tabular}

Fonte: (Adaptado do RTQ-C, 2014)

Desta forma, conclui-se que o índice de consumo da envoltória está dentro do nível de classificação A, pois o valor encontrado para a edificação analisada foi Ic $=196,56$ e o mesmo é abaixo do índice máximo para a classificação A, conforme RTQ-C (2014). No entanto, como os prérequisitos não foram atendidos totalmente, o edifício passa a ter classificação $E$ para envoltória com EqNumEnv igual a 1.

\subsection{Análise da lluminação}

Em relação ao requisito de iluminação o projeto atinge o nível $B$, pois apresenta contribuição da luz natural e divisão dos circuitos. A questão da divisão de circuitos é considerada, pois os ambientes analisados não são superiores a $250 \mathrm{~m}^{2}$, dessa forma apenas um circuito para todo o ambiente atende o solicitado pelo RTQ-C (2014) para assegurar a eficiência energética.

O método escolhido para a análise do nível de eficiência energética foi o Método da área do edifício. Desta forma, é avaliado a potência de iluminação limite para cada nível pretendido do A até o D. A carga total para o edifício é $235.100 \mathrm{~W}$, desta forma o nível de eficiência encontrado é B, com EqNumDPI igual a 4. (GASPAR, 2015) 


\subsection{Análise do condicionamento de ar}

A determinação do nível de eficiência de um sistema de condicionamento de ar depende além do nível de eficiência do equipamento, também do cumprimento do pré-requisito. Os sistemas de condicionamento de ar compostos por equipamentos do tipo janela ou split, avaliados pelo INMETRO, possuem pré-requisito apenas para nível de eficiência A. Este pré-requisito consiste em conferir se a unidade de condicionamento de janela ou a unidade condensadora do sistema split do ambiente em questão está sempre sombreada. Caso este pré-requisito não seja cumprido, o nível do equipamento cairá para B, mesmo ele tendo a etiqueta $A$ do INMETRO.

Este pré-requisito consiste em conferir se a unidade de condicionamento de janela ou a unidade condensadora do sistema split do ambiente em questão está sempre sombreada. Caso este pré-requisito não seja cumprido, o nível do equipamento cairá para $\mathrm{B}$, mesmo ele tendo a etiqueta A do INMETRO. A pontuação geral é obtida através da inserção dos dados obtidos na análise do projeto na equação geral de eficiência energética. Após o cálculo da equação geral com os dados do projeto, o resultado encontrado foi de 2,87. Desta forma de acordo com a Tabela contida no Manual, a classificação do edifício fica no Nível C.

Em relação ao condicionamento de ar, para análise do problema em estudo neste artigo, a edificação utilizará equipamentos que já possuem selo Procel com eficiência máxima, nível $A$. Desta forma, considera-se que o nível alcançado é também o nível $A$, logo será considerado o EqNumCA=5.

\section{ANÁLISE GERAL}

De forma geral a equação 1, apresenta uma pontuação extra que visa incentivar o uso de soluções que elevem a eficiência energética do edifício. A pontuação adquirida através da implementação destas bonificações variam entre 0 e 1 . Sendo: $\underline{0}$ quando não existe nenhum sistema complementar para o aumento da eficiência do edifício, e $\underline{1}$ quando uma das bonificações for implantada em sua totalidade.

A pontuação geral é obtida através da inserção dos dados obtidos na análise do projeto na equação 1 de eficiência energética que teve como resultado 2,87. Desta forma de acordo com EQC-T(2014), a classificação do edifício fica no Nível C. Sendo que, os dados dos intervalos dos níveis de eficiência para o edifício analisado são ilustrados na tabela 4. 
Tabela 4 - Dados dos intervalos dos níveis de eficiência para o edifício analisado

\begin{tabular}{lr}
\hline \multicolumn{2}{|c}{$\begin{array}{r}\text { Dados do projeto para a } \\
\text { equação geral }\end{array}$} \\
\hline EqNumEnv & 1 \\
\hline AC & 825 \\
\hline AU & 2080,19 \\
\hline APT & 1252 \\
\hline ANC & 0 \\
\hline EqNumV & 5 \\
\hline EqNumDPI & 4 \\
\hline EqNumCA & 5 \\
\hline b & 0 \\
\hline
\end{tabular}

Fonte: (Adaptado GASPAR, 2015)

\section{CONCLUSÃO}

O projeto analisado apresentou alto nível de eficiência energética para alguns itens como condicionamento de ar e iluminação. No entanto, no item da envoltória, que envolve a análise dos fechamentos e dos materiais utilizados, o nível de eficiência foi insatisfatório, devido principalmente ao material escolhido para o revestimento externo da edificação.

A avaliação através do RTQ-C possibilitou que houvesse uma análise prévia do nível de eficiência do projeto, e com isso foi possível explicitar os pontos frágeis em relação ao alcance desse objetivo. O método escolhido, o prescritivo, permite uma análise geral, sendo o mais recomendado a realização do método de simulação para resultados mais detalhados, no entanto essa metodologia ainda apresenta entraves na sua aplicação, pois exige um estudo profundo sobre arquitetura bioclimática e domínio de softwares de simulação.

Nos trabalhos futuros, recomenda-se que seja realizado além da análise prescritiva do RTQC (2014) seja realizado também a análise por meio da simulação. É recomendado também que o edifício analisado seja concebido com um material de fechamento externo mais favorável no âmbito da eficiência energética. Além disso, na parte de iluminação se houvesse uma divisão de circuitos que possibilitasse a o desligamento das luminárias próximas as janelas, também haveria uma melhora significativa no nível de eficiência. 


\section{REFERÊNCIAS}

ABESCO. Brasil desperdiça meia Itaipu por ano; Maio 2018; Disponível em: http://www.abesco.com.br/novidade/brasil-desperdica-meia-itaipu-por-ano. Acesso: 23/08/2019.

ABNT; NBR ABNT 15220/2003; Desempenho térmico de edificações, 2003.

ASHRAE90.1, Energy Standard for Buildings Except Low-Rise Residential Buildings, Disponível em: https://www.ashrae.org/resources-publications/bookstore/standard-90-1. Acesso em: 03/08/2019.

BRASIL, Lei $N^{\circ}$ 10.295, de 17 de Outubro de 2001, Dispõe sobre a Política Nacional de Conservação e Uso Racional de Energia e dá outras providências, Disponível em: http://www.planalto.gov.br/ccivil_03/LEIS/LEIS_2001/L10295.htm, Acesso em 21/03/2020.

BRASIL, Portaria n.o 126, de 19 de março de 2014. Dispõe sobre critérios e diretrizes para a obtenção do Nível de Eficiência Energética de Edifícios Comerciais, de Serviços e Públicos visando a aplicabilidade em ambientes construídos para as competições esportivas da Copa do Mundo, de 2014 e as Olímpiadas de 2016. Ministério do Desenvolvimento, Indústria e Comércio Exterior, Disponível em <http://www.inmetro.gov.br/legislacao/rtac/pdf/RTAC002100.pdf>. Acesso 03/06/2015.

BRASIL, Portaria n. 17, de 16 de janeiro de 2012, Dispõe de retificações nos Requisitos Técnicos da Qualidade para o Nível de Eficiência Energética de Edifícios Comerciais, de Serviços e Públicos (RTQ-C), aprovados pela Portaria Inmetro no 372, de 17 de setembro de 2010, Disponível em: http://www.pbeedifica.com.br/sites/default/files/projetos/etiquetagem/comercial/downloads/RT AC001787.pdf. Acesso em: 21/03/2020.

BRASIL, RIO GRANDE DO SUL, Decreto № 34.979, de 23 de novembro de 1993. Institui o Programa Estadual de Conservação de Energia nas Edificações e cria Conselho. Disponível em: http://www.al.rs.gov.br/legis/M010/M0100099.ASP?Hid_Tipo=TEXTO\&Hid_TodasNormas=14036 \&hTexto=\&Hid_IDNorma=14036. Acesso em: 21/03/2020.

CARLO, Joyce Correna e LAMBERTS, Roberto. Parâmetros e métodos adotados no regulamento de etiquetagem da eficiência energética de edifícios - parte 1: método prescritivo. Ambiente Construído, Porto Alegre, v. 10, n. 2, p. 7-26, abr./jun, 2010.

CB3e, Centro Brasileiro de Eficiência Energética em Edificações, Manual de Etiquetagem de Edificações Públicas, Gestor Público, UFSC, 2014, Disponível em: http://www.pra.ufpr.br/portal/wp-

content/uploads/2015/04/manual_etiquetagem_edificoes_publicas.pdf, Acesso em: 13/11/2019 Directiva 93/76/CEE do Conselho, de 13 de Setembro de 1993, Limitação das emissões de dióxide de carbono através do aumento da eficácia energética, Disponível em: https://eurlex.europa.eu/legal-content/PT/TXT/?uri=CELEX\%3A31993L0076. Acesso: 23/03/2020.

GASPAR, Raísa Brandão, Proposta de plano de gestão de projeto da qualidade da eficiência energética na construção de um prédio público, Pós-Graduação e em Gestão e Gerenciamento de Projetos, Escola Politécnica da Universidade Federal do Rio de Janeiro, 2015. 
LOBO, Renato Nogueirol; Gestão da qualidade; São Paulo: Editora Érica, 2010.

NAKAMURA, Natália Kokumai, MACIEL, Liliane Fernandes e CARLO, Joyce Correna, Impactos de medidas de conservação de energia propostas no PBE Edifica para o nível de eficiência energética de envoltórias de um edifício naturalmente condicionado, Ambiente Construído, Porto Alegre, v.13, n.4, p 105-119, out /dez, 2013.

PEREZ, Carmen Pedrosa; Proposta de implementação de um plano de qualidade para obras públicas; Dissertação; Programa de Pós Graduação em Construção Civil, Escola de Engenharia da Universidade Federal de Minas Gerais, Área de concentração: Construção civil, UFMG; 2011.

PICCHI, Flávio Augusto e AGOPYAN, Vahan; Sistemas da qualidade na construção de edifícios. Boletim Técnico, Departamento de Engenharia de Construção Civil; USP - São Paulo; 1993.

ROMERO, Marcelo de Andrade e REIS, Lineu Belico; Eficiência energética em edifícios; Editora Manole; São Paulo; 2012.

RTQ-C; Regulamento Técnico da Qualidade para o Nível de Eficiência Energética de Edifícios Comerciais, de Serviços e Públicos; 2014; Disponível em: http://www.pbeedifica.com.br/sites/default/files/projetos/etiquetagem/comercial/downloads/m anualv02_1.pdf, Acesso: 13/11/2019. 